\title{
Changes in the use of anti-asthmatic medication in an international cohort
}

\author{
C. Janson*, R. de Marco ${ }^{\#}$, S. Accordini ${ }^{\#}$, E. Almar ${ }^{\ddagger}$, M. Bugiani ${ }^{+}$, A. Carolei ${ }^{\S}$, \\ L. Cazzoletti ${ }^{\#}$, I. Cerveri ${ }^{f}$, A. Corsico ${ }^{f}$, E. Duran-Tauleria**, D. Gislason ${ }^{\# \#, ~}$ \\ A. Gulsvik ${ }^{\tau \uparrow}$, R. Jõgi ${ }^{++}$, A. Marinoni ${ }^{\S}$, J. Martínez-Moratalla ${ }^{\S \S}$, I. Pin ${ }^{f f}$, \\ P. Vermeire*** and D. Jarvis ${ }^{\# \# \#}$
}

ABSTRACT: The aim of this study was to describe changes in pharmacotherapy for asthma since the early 1990s in an international cohort of young and middle-aged adults.

A total of 28 centres from 14 countries participated in a longitudinal study. The study included 8,829 subjects with a mean follow-up time of 8.7 yrs. Change in the prevalence of use for medication was expressed as absolute net change ( $95 \%$ confidence interval) standardised to a 10 yr period.

The use of anti-asthmatics was found to have increased by $3.1 \%(2.4-3.7 \%)$ and the prevalence of symptomatic asthma by $4.0 \%$ (3.5-4.5\%). In the sample with asthma in both surveys $(n=423)$, the use of inhaled corticosteroids increased by $12.2 \%(6.6-17.8 \%)$. Despite this, only $17.2 \%$ were using inhaled corticosteroids on a daily basis at follow-up. Females with continuous asthma were more likely, compared with males, and smokers with asthma, to have started using inhaled corticosteroids since the first survey.

The use of anti-asthmatics has increased in a pattern consistent with current consensus on treatment. However, despite increased use of inhaled corticosteroids, a large majority of subjects with symptomatic asthma do not use this treatment on a daily basis, particularly males and smokers with asthma.

KEYWORDS: Asthma, epidemiology, inhaled corticosteroids, smoking, therapy

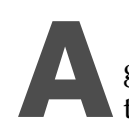
common theme in asthma management guidelines published in the 1990s [1-4] is to emphasise the use of inhaled corticosteroids (ICS) as the first line of treatment in persistent asthma. Drug sales, expressed as a daily defined dose per 1,000 inhabitants, show an increase in ICS in many countries [5-7], though it is not known to what extent regular use of ICS has actually increased in asthmatics. The European Community Respiratory Health Survey I (ECRHS I) was conducted between 1990 and 1994. In accordance with other studies [8-11], the current study found large differences in the treatment of asthma in different countries [12]. The European Community Respiratory Health Survey II (ECRHS II), a follow-up study of the subjects that were investigated in the ECRHS I, provides a unique opportunity to study changes in the treatment of asthma as reported by people with asthma in populations from a large number of different countries.

The aim of this investigation was to study how anti-asthmatic pharmacotherapy and particularly ICS have changed after the introduction of the
Global Initiative for Asthma (GINA) guidelines in an international cohort of young and middleaged adults. A secondary aim was to identify factors that were related to the use of ICS in individual participants.

\section{METHODS}

The design of ECRHS I and ECRHS II have been published in detail (fig. 1) [13, 14]. Each participant was sent a brief questionnaire (stage 1) and from those who responded, a random sample was selected to undergo a more detailed clinical examination (stage 2). In addition a "symptomatic sample", reporting symptoms of waking with shortness of breath, asthma attacks or using asthma medication in stage 1 were also studied.

In ECRHS II, subjects who had participated in stage 2 of ECRHS I, were invited to participate in the follow-up. Four centres (in Germany, the Netherlands and the USA) were not able to follow-up the whole of the eligible sample and selected a representative subsample. This analysis includes data from 28 centres in ECRHS II (table 1). The target population was 14,530
AFFILIATIONS

${ }^{\star}$ Dept of Medical Sciences Respiratory Medicine \& Allergology, Uppsala University, Uppsala, Sweden

\#University of Verona, Dept of Medicine and Public Health, Unit of Epidemiology and Statistics, Verona +Unit of Respiratory Diseases, CPAAsl4, Turin,

${ }^{\S}$ Dept of Applied Health Sciences, Faculty of Medicine, and ${ }^{f}$ Division of Respiratory Diseases, IRCCS "San Matteo" Hospital, University of Pavia, Pavia, Italy. -Unit of Epidemiology, Public Health Dept of Castilla La Mancha, Albacete, **Institut Municipal d'Investigació Mèdica (IMIM), Universitat Pompeu Fabra (UPF), Barcelona, and §§ Unit/Dept of Pneumologie, University Hospitalary Complex Albacete, Albacete, Spain.

\#\# Dept of Allergy, Respiratory Medicine and Sleep, University Hospital, Reykjavik, Iceland " Dept of Thoracic Medicine, Institute of Medicine, University of Bergen, Bergen, Norway.

+Tartu University Clinics, Lung Clinic Tartu, Estonia.

${ }^{f f}$ Dépt de Pédiatrie, CHU de Grenoble, Grenoble, France.

$* * *$ University of Antwerp (Campus Drie Eiken), Antwerp, Belgium. \#\#\# Dept of Public Health Sciences, King's College London, UK.

\section{CORRESPONDENCE}

C. Janson: Dept of Medical Sciences, Respiratory Medicine and Allergology, Akademiska sjukhuset, SE 75185 Uppsala, Sweden. Fax: 46186112819 E-mail: christer.janson@medsci.uu.se

Received:

March 182005

Accepted after revision: July 132005

SUPPORT STATEMENT

E. Duran-Tauleria has obtained funding for research unrelated to this project from GlaxoSmithKline. All other authors declare that they have no conflict of interest.

European Respiratory Journal Print ISSN 0903-1936 Online ISSN 1399-3003 


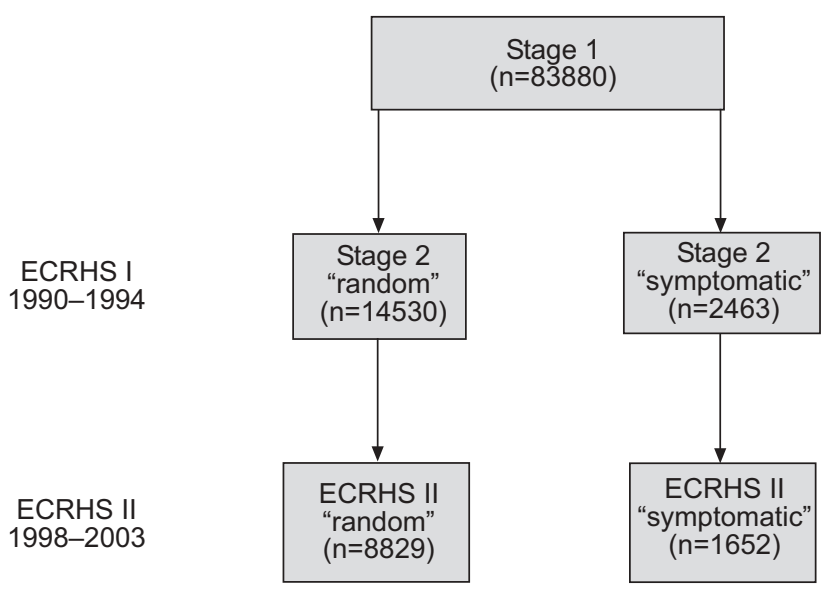

FIGURE 1. Study population in the different stages of the European Community Respiratory Health Surveys (ECRHS) I and II.

subjects from the random population that had answered questions on asthma medication in stage 2 of ECRHS I. Of these, $8,829(60.8 \%)$ supplied data on the use of medication in
ECRHS II. In addition, 2,463 subjects from the symptomatic sample had participated in ECRHS I. Of these, 1,652 (67.1\%) took part in ECRHS II (fig. 1).

\section{Questionnaire and definitions}

The subjects underwent a structured interview, which included detailed information on respiratory symptoms, asthma and asthma therapy. Pictures, samples or lists of different anti-asthmatic medications were shown to facilitate a correct answer to the therapy questions. Local ethics committees at each centre approved the study protocols.

Definition of asthma-related variables

Physician-diagnosed asthma was defined as a positive answer to the questions "Have you ever had asthma?" and "Was this confirmed by a doctor?"

Asthma-related symptoms were classified as wheeze, nocturnal chest tightness, attacks of breathlessness following activity, at rest or at night time during the previous 12 months.

Symptomatic asthma was defined physician-diagnosed asthma and asthma-related symptoms or attacks of asthma in the previous 12 months.

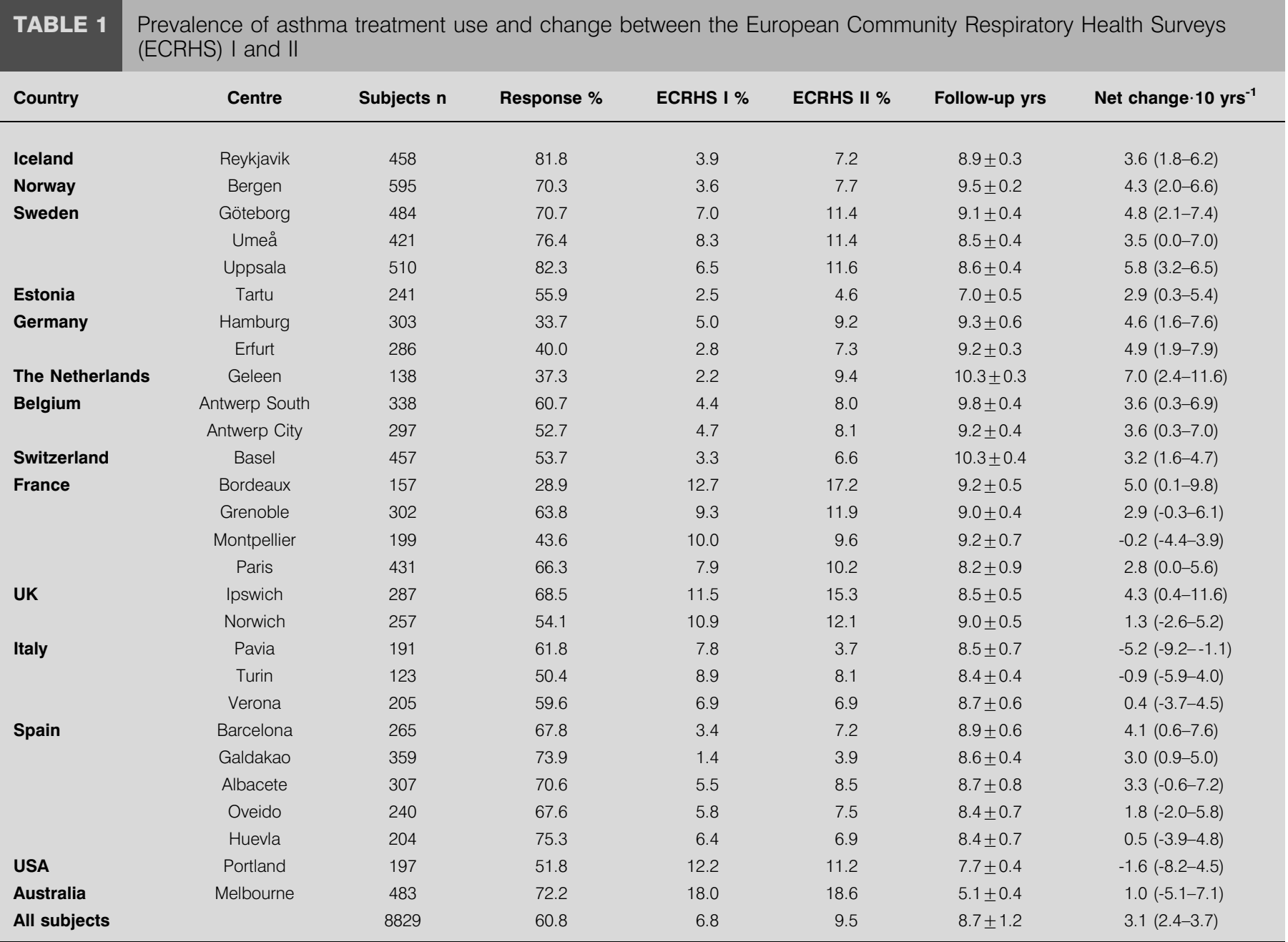

Data presented as mean \pm SD or $\%$ (95\% confidence interval), unless otherwise stated 
New asthma was categorised as symptomatic asthma in ECRHS II but not in ECRHS I.

Continuous asthma was defined as diagnosed symptomatic asthma in both surveys.

Anti-asthmatic medication was categorised as reportedly taking any of the following drugs in the previous 12 months. 1) Inhaled anti-asthmatics: short-acting $\beta_{2}$-agonist, long-acting $\beta_{2}$-agonists, anticholinergic agents, ICS and cromones. Patients who used inhalers with the combination of ICS and long-acting $\beta_{2}$-agonists were coded as using both kinds of drugs. 2) Oral anti-asthmatic medication: $\beta_{2}$-agonist, theophylline, ketotifen, antileukotrienes and oral corticosteroids. In addition, daily use of the following drugs was analysed: short-acting $\beta_{2}$-agonists, long-acting $\beta_{2}$-agonists and ICS.

Inhaled corticosteroids doses were divided into the following categories: low dose $<500 \mu \mathrm{g}$, medium dose 500-1,000 $\mu \mathrm{g}$, high dose $>1,000 \mu \mathrm{g}$, daily in doses equivalent to beclomethasone [15].

Hospitalisation was defined as reporting to have spent at least one night at hospital because of breathing problems within the previous 12 months

Doctor visits were defined as having seen a doctor because of breathing problems within the previous 12 months.

Socio-economic status was defined using information on the subject's occupation provided during ECRHS I, according to the UK social classification [16]. Using this classification the subjects were divided into: 1) professional and semiprofessionals, 2) skilled non-manual workers, 3) manual workers and 4) undefined. A low educational level was defined as having completed full time education before the age of 16 yrs [17].

Based on the information on smoking in both surveys the subjects were classified into: never-smoker, ex-smoker (before ECRHS I), quitter (between ECRHS I and II), starter (between ECRHS I and II) and persistent smoker. Since the number of subjects that started smoking between the surveys was low $(n=256)$ the starters and persistent smokers were merged together to form one category called smoker.

\section{Statistics}

Analysis was carried out using Stata 8.0. Absolute net change in treatment status per year of follow-up was estimated using population averaged, generalised estimating equations for a binomial outcome with identity link, with participants identified as the clustering factor and length of follow-up as an independent variable. Results were expressed as net change per 10 yrs of follow-up. The Wald test was used to examine differences in change of prevalence by age group and sex. To study the determinants of the use of ICS during the follow-up, the analysis was restricted to continuous asthmatics that were not using ICS in ECRHS I. A logistic regression model was fitted to the data using, as outcome, a dummy variable contrasting subjects that started to use ICS during the follow-up against never-users. Estimates by centre (random populations) or country (continuous asthmatics) were examined for heterogeneity and combined using random effect metaanalysis. The randomly selected population was used in all analyses except when analysing determinants of the use of ICS where the random and symptomatic samples were combined.

\section{RESULTS}

The analyses of the random population samples included 4,215 males and 4,614 females that participated both in ECRHS I and II. The mean $\pm \mathrm{SD}$ ages of the participants in the two surveys were $34.0 \pm 7.1$, (range 20-48) and $42.8 \pm 7.1$, (range 26-57) yrs respectively.

\section{Participants and non-participants}

The non-participants in ECRHS II were slightly younger $(32.9 \pm 7.2$ versus $33.9 \pm 7.1 \mathrm{yrs})$ and more likely to be smokers in ECRHS I (43.0 versus $35.2 \%$ ) than subjects that participated in both ECRHS I and II. There were no significant differences in sex distribution, social classification, prevalence of asthma or the use of medication between those who participated in the follow-up and those who did not. Asthmatics in ECRHS I that did not participate in the follow-up were slightly younger $(31.9 \pm 7.2$ versus $33.8 \pm 7.0 \mathrm{yrs})$ and more often smokers (39.6 versus $27.9 \%$ ) than asthmatics that participated in the follow-up.

\section{Change in anti-asthmatic treatment in the general population}

The overall use of anti-asthmatic medication increased significantly (table 1). When analysing individual centres, an increased prevalence of treatment was found in most. Significant between-centre heterogeneity was found $(p=0.04)$, but this heterogeneity was explained by a significantly reduced prevalence of medication in one centre (Pavia, Italy) and exclusion of this centre from the analysis showed no heterogeneity $(p=0.58)$. Similar increases were observed in both sexes at all ages.

\section{Therapy of asthma in different countries}

In the random sample of ECRHS I, 894 subjects had symptomatic asthma and 494 of these subjects were reinvestigated in ECRHS II (fig. 2). The overall prevalences of symptomatic asthma in subjects from the random sample of ECRHS I who were investigated both in the ECRHS I and II, were 5.5 and $9 \%$ respectively. The absolute net change was 4.0 $(3.5,4.5) \% \cdot 10 \mathrm{yrs}^{-1}$. Of the 794 subjects that had symptomatic asthma in ECRHS II, 370 (45.9\%) had new asthma and 424 had asthma in both surveys (fig. 2). Of the subjects with new asthma, 51 had a diagnosis of asthma but no symptoms in ECRHS I, whilst 319 had been diagnosed as having asthma between the two surveys. The prevalence of use of short-acting $\beta_{2}$-agonists and oral anti-asthmatics was higher in the group of subjects with continuous asthma than in those with new asthma (57.2 versus $44.6 \%, p=0.0001$ and 11.1 versus $6.6 \%$, $\mathrm{p}=0.03$, respectively), whereas there was no significant difference in the use of ICS. The prevalence of ICS used daily was $15.3 \%$ (12.9 in the new and $17.2 \%$ in the group with continuous asthma $(\mathrm{p}=0.09))$.

The prevalence of use of ICS varied from almost $50 \%$ in the populations of asthmatics in the Netherlands, Belgium, UK and Sweden to $<20 \%$ in the Italian and Swiss asthmatic population samples (table 2). Less than half of those that had used ICS in the previous 12 months were using them on a daily basis during the last 3 months (table 2). Among the 121 


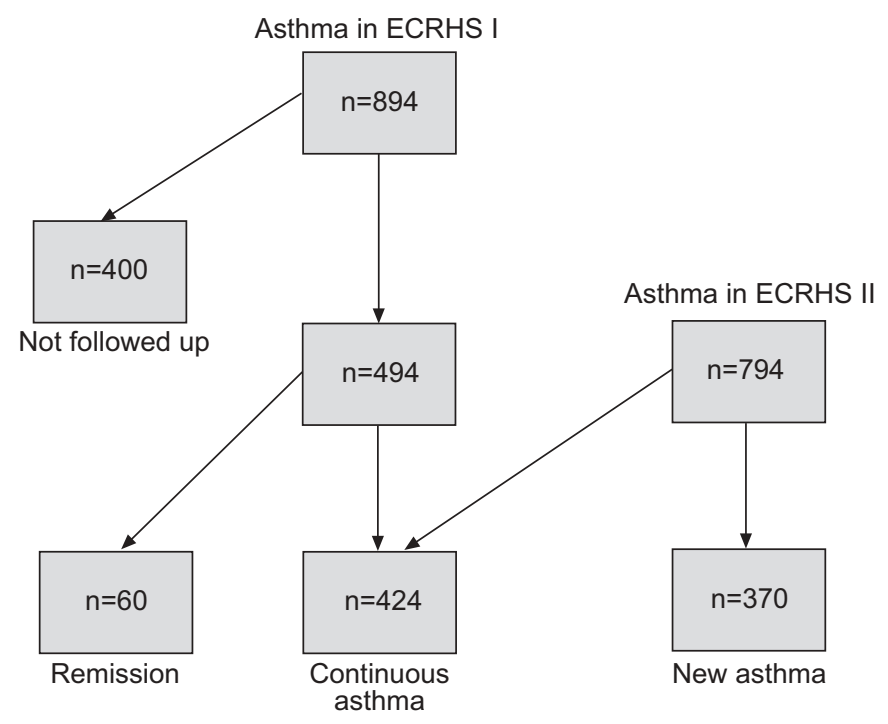

FIGURE 2. Follow-up of asthmatics in the European Community Respiratory Health Survey (ECRHS) I and change in asthma status between ECRHS I and II.

subjects that were taking ICS daily in the ECRHS II, 38, 49 and $14 \%$ were using low, moderate and high doses, respectively.

\section{Change in anti-asthmatic treatment in subjects with continuous asthma}

A total of 494 subjects in the random sample had symptomatic asthma in ECRHS I. Of these, 424 (87.8\%) still had symptomatic asthma at the ECRHS II survey (fig. 2). In this group, there was a significantly increased use of ICS and a decreased use of oral $\beta_{2}$-agonists and theophylline. Despite a significant increase in daily use of ICS (fig. 3), only $17 \%$ of subjects with continuous asthma used ICS on a daily basis (table 3). There was no country heterogeneity in change in daily use of ICS or any other type of therapy $(p>0.1)$ except for a change in any use of ICS within the last 12 months (test for heterogeneity $p=0.001$ ), chiefly explained by a very large increase observed in Belgium. Excluding the Belgian centres, the increase in the use of ICS was still highly significant (9.7 (4.0-15.3), without any country heterogeneity $(\mathrm{p}>0.1))$.

\section{Change in asthma-related outcomes and health utilisation}

Patients with continuous asthma reported significantly less asthma attacks in the second survey compared with the first, whereas no significant change was found in hospitalisations or in the proportion that had seen a doctor within the previous 12 months (table 4). Only six out of the 209 patients that had not seen a doctor had seen a nurse or a physiotherapist within the previous 12 months. The decline in the proportion of patients with more than four asthma attacks was larger in the group of patients that had used ICS in both surveys compared with patients that had not used ICS in any of the surveys (-38.6 $(-58.2,-17.2) \%$ versus $-10.9(-24.9,4.7) \%, p=0.01)$. The sample was too small to test the association between change in asthma attacks and daily use of ICS or ICS use and hospitalisations.

\section{Determinants for the start of use of ICS}

When combining the random and symptomatic population samples, 1,089 subjects fulfilled the criteria for symptomatic asthma at the first survey and of those, 969 (89\%) still had symptomatic asthma. In this group, 150 had started using ICS since the first survey. Males and smokers were less likely to have started using ICS and this pattern was consistent across countries (test for heterogeneity $\mathrm{p}>0.1$; table 5). Restricting the analysis to daily use of ICS gave similar results, with an increased likeliness in females (OR (95\% CI): 2.04 (1.07-3.89))

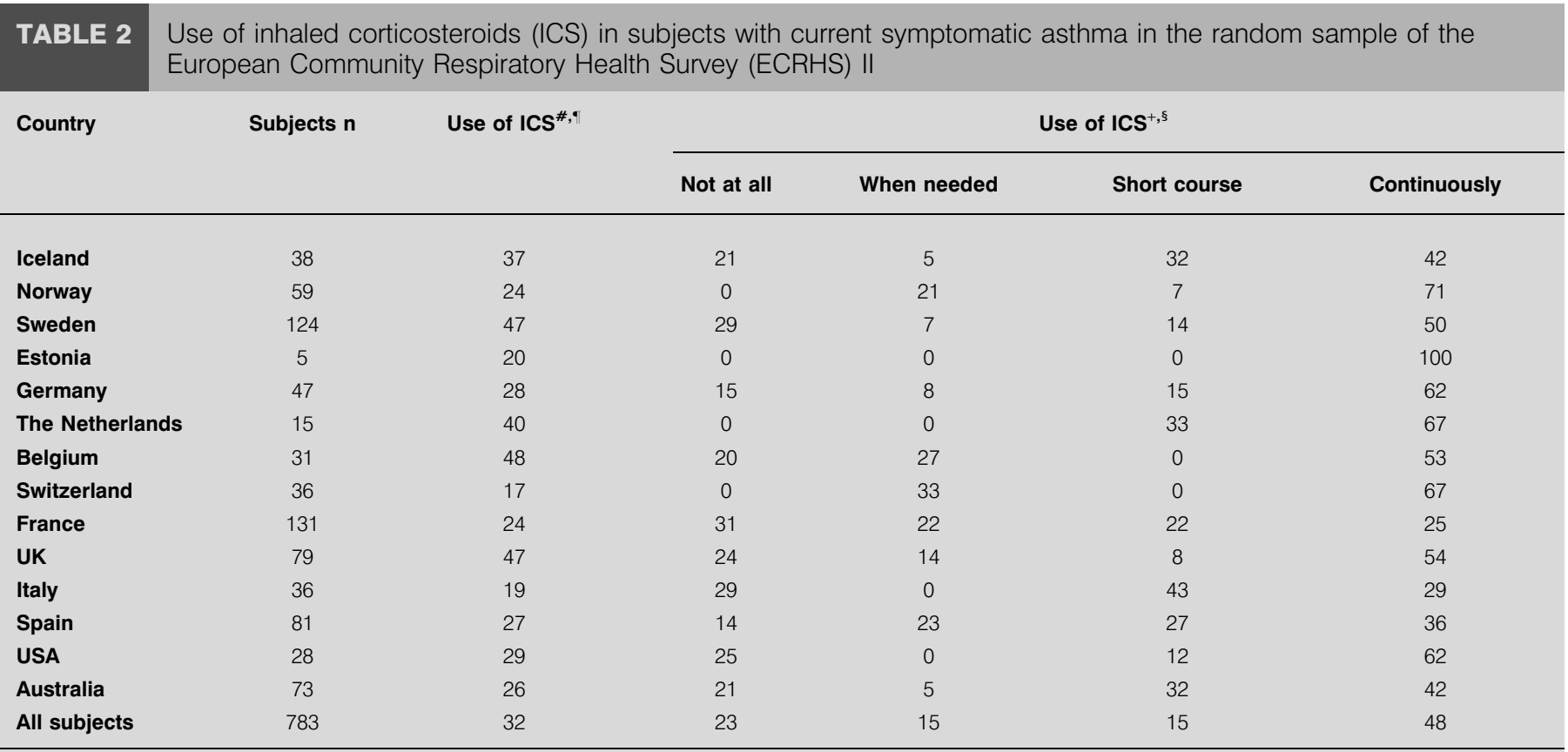

All data presented as per cent unless otherwise specified. ${ }^{\#}$ : in previous 12 months; ${ }^{\bullet}: \mathrm{n}=783{ }^{+}{ }^{+}$: during last 3 months in subjects that have taken ICS during the previous 12 months; ${ }^{\text {s: }} \mathrm{n}=252$. 


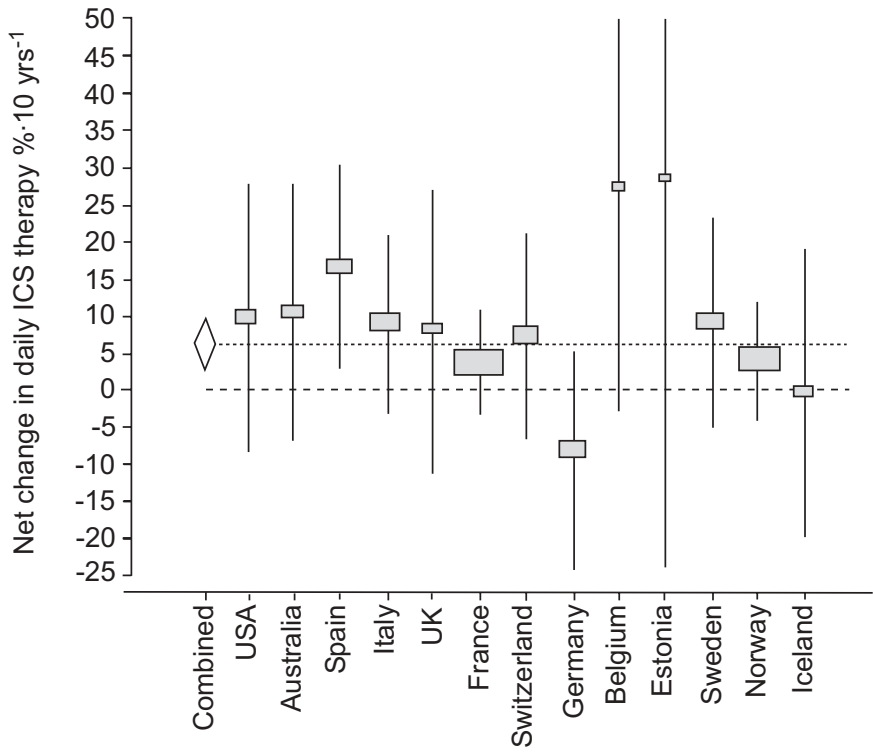

FIGURE 3. Net change in daily use of inhaled corticosteroids (ICS) in the continuous asthmatics from the random sample of the European Community Respiratory Health Survey (ECRHS) II, with the 95\% confidence interval (CI) of the centre. The area of each square is proportional to the reciprocal of the variance of the estimate for the centre. ….......: combined random-effects estimate; $\diamond:$ has the width of its $95 \% \mathrm{Cl}$

and a decreased likeliness in smokers (OR (95\% CI): 0.37 (0.16$0.86)$ ) to have started using ICS on a daily basis.

\section{DISCUSSION}

In a large, multicentre study, the proportion of participants reporting the use of medications for asthma has increased over an 8-yr period. At the same time there has been an increase in symptomatic asthma in the study population. Despite a widespread increase in the use of anti-asthma medication, only one in six with diagnosed asthma and symptoms highly suggestive of current active asthma, were taking inhaled steroids daily. Differences in the use of inhaled corticosteroids between males and females and smokers and nonsmokers that were identified at baseline are still present in this cohort.

To the best of the current authors' knowledge, ECRHS II is the first population-based study of change in asthmatic pharmacotherapy in an international cohort. The time period studied is of particular interest, since GINA guidelines were introduced at the time of the first survey [3]. The main strength of this investigation is that it is prospective and the methodology of the study is the same in both surveys. However, a drawback with this approach is that there were few indicators of asthma severity in the first survey. Low-response rates in some centres may be of concern, although in general, the direction of change was consistent in centres and countries with low and high response rates. Differences between responders and nonresponders at baseline were relatively small, although there was an under-representation of males and smokers among those who participated in ECRHS II. This may have caused an overestimation of the overall change in use of drugs but the associations of sex and smoking with change are unlikely to be altered.

The current authors' definition of asthma was based on the combination of a physician's reported diagnosis and current asthma-related symptoms. The same definition was used in the previous study of ECRHS I [12] and has in previous studies' populations been shown to have a relatively low sensitivity but high specificity $[18,19]$. An increase in the use of reported asthma attacks and "any medicine for asthma" in this

TABLE 3 Prevalence and change in different types of anti-asthmatic drugs in subjects with continuous symptomatic asthma from the random sample

\begin{tabular}{|c|c|c|c|}
\hline & ECRHS I & ECRHS II & Net change $\cdot 10 \mathrm{yr}^{-1}$ \\
\hline \multicolumn{4}{|c|}{ Medication used in the last 12 months } \\
\hline Inhaled anti-asthmatics & 61.9 & 64.5 & $2.7(-2.8-8.2)$ \\
\hline Inhaled short-acting $\beta_{2}$-agonists & 55.8 & 57.2 & $0.9(-4.7-6.6)$ \\
\hline Inhaled long-acting $\beta_{2}$-agonists & & 13.6 & \\
\hline Inhaled corticosteroids & 22.5 & 32.6 & $12.2(6.6-17.8)$ \\
\hline Inhaled cromones & 6.1 & 2.4 & $-4.9(-7.8--2.1)$ \\
\hline Oral anti-asthmatics & 15.2 & 11.1 & $-4.1(-8.7-0.5)$ \\
\hline Oral $\beta_{2}$-agonists & 5.5 & 1.5 & $-4.2(-6.7--1.6)$ \\
\hline Oral theophylline & 8.2 & 2.6 & $-6.2(-9.4--3.0)$ \\
\hline Oral anti-leukotrienes & & 1.2 & \\
\hline Inhaled corticosteroids & 10.3 & 17.2 & $8.1(3.7-12.4)$ \\
\hline
\end{tabular}

Data presented as \% or \% (95\% confidence interval). Total number of subjects was 423. ECRHS: European Respiratory Health Survey. 


\begin{tabular}{|c|c|c|c|c|}
\hline \multirow[t]{2}{*}{ TABLE 4} & \multicolumn{4}{|c|}{$\begin{array}{l}\text { Prevalence and change in asthma-related } \\
\text { outcomes and doctor visits in subjects with } \\
\text { continuous symptomatic asthma from the } \\
\text { random sample }\end{array}$} \\
\hline & & ECRHS I & ECRHS II & Net change $\cdot 10 \mathrm{yr}^{-1}$ \\
\hline \multicolumn{2}{|c|}{ Hospitalisations } & 2.2 & 1.4 & $-1.1(-3.2-1.1)$ \\
\hline \multicolumn{2}{|c|}{$\begin{array}{l}\text { More than one } \\
\text { asthma attack }\end{array}$} & 43.4 & 33.9 & $-11.2(-17.5--4.9)$ \\
\hline \multicolumn{2}{|c|}{$\begin{array}{l}\text { More than four } \\
\text { asthma attacks }\end{array}$} & 28.7 & 16.0 & $-14.9(-20.5--9.1)$ \\
\hline \multicolumn{2}{|c|}{ Seen by a doctor } & 40.6 & 35.6 & $-4.4(-11.0-2.3)$ \\
\hline
\end{tabular}

Data presented as $\%$ or $\%$ ( $95 \%$ confidence interval). Total number of subjects was 423 . The recall period was 12 months for all variables. ECRHS: European Respiratory Health Survey.

population has been shown in a recent analysis of data from both postal surveys (stage 1) in ECRHS I and II [20]. It is difficult to know whether the increased prevalence of asthma in the previous and present report is related to an actual increase in asthma or a change in diagnostic threshold, with more subjects with mild disease being diagnosed and treated for asthma. In contrast to the present investigation, the postal questionnaire did not include information on the use of specific drugs, such as ICS or smoking history [20].

The current authors have observed a substantial increase in the use of anti-asthmatics. The observed change in utilisation of

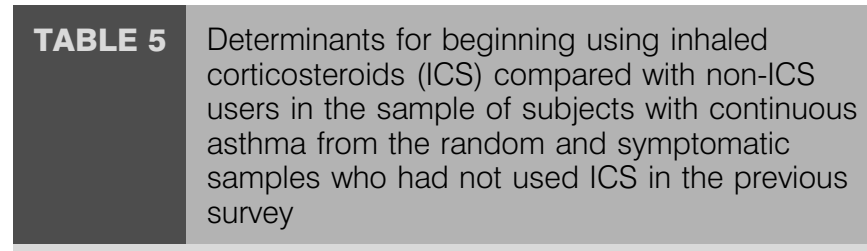

Use of ICS OR $(95 \% \mathrm{Cl})$

$\begin{array}{lc}\text { Age 10-yr increase } & 1.21(0.85-1.74) \\ \text { Female verus male } & 2.20(1.36-3.55) \\ \text { Never-smoker } & 1 \\ \text { Ex-smoker } & 0.96(0.52-1.75) \\ \text { Quitter } & 0.74(0.35-1.59) \\ \text { Smoker } & 0.44(0.25-0.79) \\ \text { Professionals and semiprofessionals } & 1 \\ \text { Non-manual } & 1.12(0.60-2.08) \\ \text { Manual } & 0.85(0.46-1.57) \\ \text { Low educational status } & 1.04(0.48-2.24) \\ \text { No asthma attacks in the previous year } & 1 \\ \text { One to four asthma attacks } & 1.54(0.91-2.61) \\ \text { More than four asthma attacks } & 2.06(1.15-3.68) \\ \text { Early onset asthma } \leqslant \mathbf{1 8} \text { yrs old } & 1.06(0.65-1.73)\end{array}$

Total subjects $n=517$. Adjusted for centre, sample, length of follow-up and the variables in the table. ${ }^{\#}$ : entered separately in the table, replacing occupational status. anti-asthmatics is probably a combined effect of an increased prevalence of diagnosed asthma and a greater chance of receiving inhaled corticosteroids once diagnosed. This result is in accordance with both the recommendations from guidelines [1-4] and reports of national trends in sales of anti-asthmatics [5-7]. The current authors also found indications that asthma control has improved, since people with asthma in both surveys reported fewer asthma attacks at follow-up. This was most noticeable in patients that used ICS in both surveys. Because of the time period studied it is likely that these improvements are related to guideline disseminations. It is also possible that these improvements are in part related to increased awareness of asthma in the current study's cohort as an effect of being a participant in a longitudinal study [21]. However, a study from New Zealand using ECRHS I data did not find that repeated measurements introduced a bias in prevalence rates of asthma and respiratory symptoms compared with those obtained in a similar population studying only one occasion [22].

However, the present study suggests that treatment reported by many asthmatics is far from ideal. Amongst current symptomatic asthmatics, only one in six reported taking them on a daily basis. Other reports have shown that inhaled corticosteroids are only used by a small proportion of asthmatics in the general population [12, 23, 24], perhaps due to relatively mild disease in some patients. Few of the subjects from the current study were hospitalised for asthma but asthma that prompts prescription of inhaled steroids is likely to cause symptoms severe enough to influence an individual's health. Inhaled corticosteroids are of less therapeutic value if not taken daily, and failure to do so will be less likely to ameliorate symptoms. As found in ECRHS I [12], the majority of patients had not seen a doctor or any other health professional because of their asthma in the last 12 months. Lack of regular medical review may be a reason for the failure to report the use of ICS as recommended.

Although some countries are represented by only one centre, there is evidence that there are marked national differences in the use of ICS by physician-diagnosed asthmatics. Despite general increases in the use of ICS and wide dissemination of clear clinical guidelines for the treatment of asthma, the pattern for higher usage of steroid inhalers in Northern Europe compared with Southern Europe that was noted in the early 1990s is still apparent almost 10 yrs later [12]. There are several possible explanations for these findings, such as different therapy traditions or cultural differences at patient level, or at the physician level. A geographical variation in asthma severity is also another possible explanation.

The current study also shows that as physicians across Europe are increasingly prescribing ICS they are decreasing the prescribtion of other drugs, such as cromones, oral $\beta_{2}$-agonists and theophylline. The decreased use of the two latter drugs is consistent with the recommendations of the GINA guidelines [3].

In the current investigation, it was observed that females with asthma were more likely to have started using ICS when compared with males. A higher use of ICS in females than in males was also found in a recent study in the UK and the Netherlands [7]. Like MARKS et al. [25], the current authors 
found that a lower proportion of asthmatic smokers were using ICS compared with nonsmoking asthmatics. Lower usage of anti-asthmatics in smokers was also found in a previous investigation [26]. This may be explained by a reduced therapeutic effect in smokers [27] or because smokers are less perceptive and therefore less troubled by bronchoconstriction [28]. Doctors may be more reluctant to introduce antiasthmatics for symptomatic smokers and instead concentrate on smoking cessation. Some of the smokers may have chronic obstructive pulmonary disease rather than asthma but as this population was relatively young when diagnosed as having asthma, the proportion of subjects misclassified in this way is probably relatively low. No association was found between socio-economic status and the use of ICS.

The current authors conclude that the prevalences of both diagnosed symptomatic asthma and anti-asthmatic medication have increased in this international cohort. The use of drugs for the treatment of asthma and the level of asthma control, has increased in a pattern consistent with current consensus on treatment. However, despite increased use of inhaled corticosteroids, a large majority of subjects with continuous symptomatic asthma do not use this treatment on a daily basis, particularly males and smokers with asthma. The prognostic implication of these findings remains to be investigated.

\section{ACKNOWLEDGEMENTS}

The Coordinating Centre was made up of the following people. Project Leader: P. Burney; Statistician: S. Chinn; Principal Investigator: D. Jarvis; Project Co-ordinator: J. Knox; Principal Investigator: C. Luczynska; Assistant Statistician: J. Potts; Data Manager: S. Arinze.

Members of the Steering Committee for the ECRHS II were as follows. U. Ackermann-Liebrich (University of Basel, Basel, Switzerland), J.M. Antó, (Institut Municipal d'Investigació Mèdica (IMIM-IMAS) and Universitat Pompeu Fabra (UPF), Barcelona, Spain), P. Burney (King's College London, London, UK), I. Cerveri (University of Pavia, Pavia, Italy), S. Chinn (King's College London), R. de Marco (University of Verona, Verona, Italy), T. Gislason (Iceland University Hospital, Reykjavík, Iceland), J. Heinrich (GSF - Institute of Epidemiology, Munich, Germany), C. Janson (Uppsala University, Uppsala, Sweden), D. Jarvis (King's College London), J. Knox (King's College London), N. Künzli (University of Southern California, Los Angeles, USA), B. Leynaert (Institut National de la Santé et de la Recherche Médicale (INSERM), Paris, France), C. Luczynska (King's College London), F. Neukirch (INSERM), J. Schouten (University of Groningen, Groningen, the Netherlands), J. Sunyer (IMIM-IMAS and UPF), C. Svanes (University of Bergen, Bergen, Norway), P. Vermeire (University of Antwerp, Antwerp, Belgium), M. Wjst (GSF - Institute of Epidemiology).

The principal investigators and senior scientific team were as follows.

South Antwerp and Antwerp City, Belgium: P. Vermeire, J. Weyler, M. Van Sprundel, V. Nelen. Aarhus, Denmark: E.J. Jensen. Tartu, Estonia: R. Jogi, A. Soon. Paris, France: F. Neukirch, B. Leynaert, R. Liard, M. Zureik. Grenoble,
France: I. Pin, J. Ferran-Quentin. Erfurt, Germany: J. Heinrich, M. Wjst, C. Frye, I. Meyer. Iceland, Reykjavík: T. Gislason, E. Björnsson, D. Gislason, T. Blöndal, A. Karlsdottir. Turin, Italy: M. Bugiani, P. Piccioni, E. Caria, A. Carosso, E. Migliore, G. Castiglioni. Verona, Italy: R. de Marco, G. Verlato, E. Zanolin, S. Accordini, A. Poli, V. Lo Cascio, M. Ferrari. Pavia, Italy: A. Marinoni, S. Villani, M. Ponzio, F. Frigerio, M. Comelli, M. Grassi, I. Cerveri, A. Corsico. Groningen and Geleen, the Netherlands: J. Schouten, M. Kerkhof. Bergen, Norway: A. Gulsvik, E. Omenaas, C. Svanes, B. Laerum. Barcelona, Spain: J.M. Antó, J. Sunyer, M. Kogevinas, J.P. Zock, X. Basagana, A. Jaen, F. Burgos. Huelva, Spain: J. Maldonado, A. Pereira, J.L. Sanchez. Albacete, Spain: J. Martinez-Moratalla Rovira, E. Almar. Galdakao, Spain: N. Muniozguren, I. Urritia. Oviedo, Spain: F. Payo. Uppsala, Sweden: C. Janson, G. Boman, D. Norbäck, M. Gunnbjornsdottir. Göteborg, Sweden: K. Torén, L. Lillienberg, A.C. Olin, B. Balder, A. Pfeifer-Nilsson, R. Sundberg. Umea, Sweden: E. Norrman, M. Söderberg, K. Franklin, B. Lundbäck, B. Forsberg, L. Nyström. Basel, Switzerland: N. Künzli, B. Dibbert, M. Hazenkamp, M. Brutsche, U. Ackermann-Liebrich. Norwich, UK: D. Jarvis, B. Harrison. Ipswich, UK: D. Jarvis, R. Hall, D. Seaton.

The centres that took part at their own expense were as follows. Melbourne, Australia: M. Abramson, R. Woods, E.H. Walters, F. Thien. Bordeaux, France: A. Taytard, C. Raherison. Montpellier, France: J. Bousquet, P. Demoly. Hamburg, Germany: K. Richter. Portland, USA: M. Osborne, S. Buist, W. Vollmer, L. Johnson.

The coordination of ECRHS II was supported by the European Commission, as part of their Quality of Life programme. The following bodies funded the local studies in ECRHS II. Aarhus, Denmark: Danish Lung Association. Albacete, Spain: Fondo de Investigaciones Santarias (FIS) (grant code: 97/0035-01, 99/0034-01 and 99/0034-02), Hospital Universitario de Albacete, Consejeria de Sanidad. Antwerp, Belgium: FWO (Fund for Scientific Research)Flanders Belgium (grant code: G.0402.00), University of Antwerp, Flemish Health Ministry. Barcelona, Spain: Sociedad Española de Neumología y Cirugia Torácica (SEPAR), Public Health Service (grant code: R01 HL6263301), FIS (grant code: 97/0035-01, 99/0034-01 and 99/0034-02), CIRIT (grant code: 1999SGR 00241). Basel, Switzerland: Swiss National Science Foundation, Swiss Federal Office for Education \& Science, Swiss National Accident Insurance Fund (SUVA). Bergen, Norway: Norwegian Research Council, Norwegian Asthma \& Allergy Association (NAAF). Bordeaux, France: Institut Pneumologique d'Aquitaine. Erfurt, Germany: GSF-National Research Centre for Environment \& Health, Deutsche Forschungsgemeinschaft (DFG) (grant code FR 1526/1-1). Galdakao, Spain: Basque Health Dept. Göteborg, Sweden: Swedish Heart Lung Foundation, Swedish Foundation for Health Care Sciences \& Allergy Research, Swedish Asthma \& Allergy Foundation, Swedish Cancer \& Allergy Foundation. Grenoble, France: Programme Hospitalier de Recherche Clinique-DRC de Grenoble 2000 no. 2610, Ministry of Health, Direction de la Recherche Clinique, Ministere de l'Emploi et de la Solidarite, Direction Generale de la Sante, CHU de Grenoble, Comite des Maladies Respiratoires de l'Isere. Hamburg, 
Germany: GSF-National Reasearch Centre for Environment \& Health, DFG (grant code: MA 711/4-1). Ipswich and Norwich, UK: Asthma UK. Huelva, Spain: FIS (grant code: 97/0035-01, 99/0034-01 and 99/0034-02). Melbourne, Australia: National Health and Medical Research Council of Australia. Montpellier, France: Programme Hospitalier de Recherche Clinique-DRC de Grenoble 2000 no. 2610, Ministry of Health, Direction de la Recherche Clinique, CHU de Grenoble, Ministere de l'Emploi et de la Solidarite, Direction Generale de la Sante, Aventis, Direction Régionale des Affaires Sanitaires et Sociales Languedoc-Roussillon. Oviedo, Spain: FIS (grant code: 97/0035-01, 99/0034-01 and 99/003402). Paris, France: Ministere de l'Emploi et de la Solidarite, Direction Generale de la Sante, UCB-Pharma, Aventis, Glaxo France, Programme Hospitalier de Recherche Clinique-DRC de Grenoble 2000 no. 2610, Ministry of Health, Direction de la Recherche Clinique, CHU de Grenoble. Pavia, Italy: GlaxoSmithKline Italy, Italian Ministry of University and Scientific and Technological Research (MURST), Local University Funding for research 1998 \& 1999. Portland, USA: American Lung Association of Oregon, Northwest Health Foundation, Collins Foundation, Merck Pharmaceutical. Reykjavik, Icelance: Icelandic Research Council, Icelandic University Hospital Fund. Tartu, Estonia: Estonian Science Foundation (grant code no 4350). Turin, Italy: ASL 4 Regione Piemonte, AO CTO/ICORMA Regione Piemonte, Ministero dell'Università e della Ricerca Scientifica, Glaxo Wellcome spa. Umeå, Sweden: Swedish Heart Lung Foundation, Swedish Foundation for Health Care Sciences \& Allergy Research, Swedish Asthma \& Allergy Foundation, Swedish Cancer \& Allergy Foundation. Uppsala, Sweden: Swedish Heart Lung Foundation, Swedish Foundation for Health Care Sciences \& Allergy Research, Swedish Asthma \& Allergy Foundation, Swedish Cancer \& Allergy Foundation. Verona, Italy: University of Verona, MURST, GlaxoSmithKline Italy.

Financial support for ECRHS I and for centres in ECRHS II was provided by the following: Belgium: Belgian Science Policy Office, National Fund for Scientific Research. France: Ministère de la Santé, Glaxo France, Insitut Pneumologique d'Aquitaine, Contrat de Plan Etat-Région Languedoc-Rousillon, CNMATS, CNMRT (90MR/10, 91AF/6), Ministre delegué de la santé, RNSP. Germany: GSF, Bundesminister für Forschung und Technologie. Italy: Ministero dell'Università e della Ricerca Scientifica e Tecnologica, CNR, Regione Veneto grant RSF n. 381/05.93. Norway: Norwegian Research Council project no. 101422/310. The Netherlands: Dutch Ministry of Wellbeing, Public Health and Culture. Spain: Ministero Sanidad y Consumo FIS (grants \#91/0016060/00E-05E and \#93/0393), and grants from Hospital General de Albacete, Hospital General Juan Ramón Jiménenz, Consejeria de Sanidad Principado de Asturias. Sweden: The Swedish Medical Research Council, the Swedish Heart Lung Foundation, the Swedish Association against Asthma and Allergy. Switzerland: Swiss National Science Foundation grant 402628099 National Asthma Campaign. UK: British Lung Foundation, Department of Health, South Thames Regional Health Authority. USA: United States Department of Health, Education and Welfare Public Health Service (grant \#2 S07 RR05521-28).

\section{REFERENCES}

1 British Thoracic Society. Guidelines on the management of asthma. Thorax 1993; 48: Suppl. 2, S1-S24.

2 Medical Products Agency. Pharmacological treatment of bronchial asthma II. Issue no. 1. Uppsala, Medical Products Agency, 1993.

3 National Institute of Health National Heart, Lung and Blood Institute, Global Initiative for asthma. NIH publication number 95-3659. Bethesda, USA, 1995.

4 Boulet LP, Becker A, Berube D, Beveridge R, Ernst P. Canadian Asthma Consensus Report, 1999. Canadian Asthma Consensus Group. CMAJ 1999; 161: Suppl. 11, S1-S61.

5 Majeed A, Ferguson J, Field J. Prescribing of beta-2 agonists and inhaled steroids in England: trends between 1992 and 1998, and association with material deprivation, chronic illness and asthma mortality rates. J Public Health Med 1999; 21: 395-400.

6 Stafford RS, Ma J, Finkelstein SN, Haver K, Cockburn I. National trends in asthma visits and asthma pharmacotherapy, 1978-2002. J Allergy Clin Immunol 2003; 111: 729-735.

7 van Staa TP, Cooper C, Leufkens HG, Lammers JW, Suissa S. The use of inhaled corticosteroids in the United Kingdom and the Netherlands. Respir Med 2003; 97: 578-585.

8 Vermeire PA, Wittesaele WM, Janssens E, De Backer WA. European audit of asthma therapy. Chest 1986; 90: Suppl. 5, 58S-61S.

9 Ruggieri F, .Hindle M. Diagnosis and treatment of asthma across Europe. Eur Respir J 1989; 2: Suppl. 6, 536s-539s.

10 Vermeire P. Differences in asthma management around the world. Eur Respir Rev 1994; 4: 279-281.

11 Vermeire PA, Rabe KF, Soriano JB, Maier WC. Asthma control and differences in management practices across seven European countries. Respir Med 2002; 96: 142-149.

12 Janson C, Chinn S, Jarvis D, Burney P. Physiciandiagnosed asthma and drug utilization in the European Community Respiratory Health Survey. Eur Respir J 1997; 10: 1795-1802.

13 Burney PG, Luczynska C, Chinn S, Jarvis D. The European Community Respiratory Health Survey. Eur Respir J 1994; 7: 954-960.

14 The European Community Respiratory Health Survey Steering Committee. The European Community Respiratory Health Survey II. Eur Respir J 2002; 20: 1071-1079.

15 Global Initiative For Asthma. Data on inhaled corticosteroids doses. www.ginasthma.com. Date accessed: November 2004. Date last updated: October 2004.

16 Liberatos P, Link BG, Kelsey JL. The measurement of social class in epidemiology. Epidemiol Rev 1988; 10: 87-121.

17 De Marco R, Accordini S, Cerveri I. An international survey of chronic obstructive pulmonary disease in young adults according to GOLD stages. Thorax 2004; 59: 120-125.

18 Toren K, Brisman J, Jarvholm B. Asthma and asthma-like symptoms in adults assessed by questionnaires. A literature review. Chest 1993; 104: 600-608.

19 De Marco R, Cerveri I, Bugiani M, Ferrari M, Verlato G. An undetected burden of asthma in Italy: the relationship between clinical and epidemiological diagnosis of asthma. Eur Respir J 1998; 11: 599-605. 
20 Chinn S, Jarvis D, Burney P. Increase in diagnosed asthma but not in symptoms in the European Community Respiratory Health Survey. Thorax 2004; 59: 646-651.

21 Murray M, Swan AV, Kiryluk S, Clarke GC. The Hawthorne effect in the measurement of adolescent smoking. J Epidemiol Com Health 1988; 42: 304-306.

22 Sears MR, Lewis S, Herbison GP. Comparison of reported prevalences of recent asthma in longitudinal and crosssectional studies. Eur Respir J 1997; 10: 51-54.

23 Rabe KF, Vermeire PA, Soriano JB, Maier WC. Clinical management of asthma in 1999: the Asthma Insights and Reality in Europe (AIRE) study. Eur Respir J 2000; 16: 802-807.

24 Ställberg B, Nystrom KU, Olsson P, Gottberg L, Ronmark E, Lundback B. Living with asthma in Sweden-the ALMA study. Respir Med 2003; 97: 835-843.
25 Marks GB, Burney PG, Premaratne UN, Simpson J, Webb J. Asthma in Greenwich, UK: impact of the disease and current management practices. Eur Respir J 1997; 10: 1224-1229.

26 Janson C, Chinn S, Jarvis D, Burney P. Individual use of antiasthmatic drugs in the European Community Respiratory Health Survey. Eur Respir J 1998; 12: 557-563.

27 Pedersen B, Dahl R, Karlstrom R, Peterson CG, Venge P. Eosinophil and neutrophil activity in asthma in a one-year trial with inhaled budesonide. The impact of smoking. Am J Respir Crit Care Med 1996; 153: 1519-1529.

28 Massasso DH, Salome CM, King GG, Seale JP, Woolcock AJ. Perception of brochodilation in subjects with asthma and smokers with airflow limitation. Respirology 1999; 4: 117-124. 